\title{
Estimating the Gender Distribution of Patients with Wild-Type Transthyretin Amyloid Cardiomyopathy: A Systematic Review and Meta- Analysis
}

Florint Kroi · Nils Fischer • Ana Gezin • Mahmoud Hashim •

Mark Hermannes Rozenbaum

Received: October 8, 2020 / Published online: December 14, 2020

(C) The Author(s) 2020

\section{ABSTRACT}

Introduction: This study investigates the gender distribution in patients diagnosed with wild-type transthyretin amyloidosis cardiomyopathy (ATTRwt).

Methods: A systematic review and meta-analysis of the male proportion in diagnosed ATTRwt patients were conducted. To avoid overlapping population, pooled estimates in the primary analysis were based on all unique studies. In secondary analyses, we considered predefined subsets of studies based on study sample size, recruitment years, geography, study design, age at diagnosis, and method of diagnosis. Additional meta-regression analyses were tested for potential determinants of gender distribution.

Electronic supplementary material The online version of this article (https://doi.org/10.1007/s40119020-00205-3) contains supplementary material, which is available to authorized users.

F. Kroi · A. Gezin · M. Hashim

Ingress-Health, Rotterdam, The Netherlands

N. Fischer

Pfizer, NewYork, USA

e-mail: nils.fischer@pfizer.com

M. H. Rozenbaum ( $\square)$

Pfizer, Rotterdam, The Netherlands

e-mail: mark.rozenbaum@pfizer.com
Results: Twenty-eight unique studies (2542 patients) were included in the meta-analysis. Male proportion in patients with ATTRwt was 86.9\% (95\% confidence interval 81.5-91.6\%). Studies, including patients older than 80 years at diagnosis, had a $29.1 \%$ ( $p$ value $<0.001)$ lower male proportion compared to studies, including younger patients. After adjusting for age, studies using autopsy as a method of diagnosis had a $21.1 \%$ ( $p$ value 0.002 ) lower male proportion compared to other studies.

Conclusions: Studies conducted to date suggest ATTRwt disproportionally affects males. The proportion of males was significantly impacted by the age at diagnosis and method diagnosis, which may suggest important gender-based differences in the clinical manifestation and diagnostic challenges of ATTRwt in females that warrant future research.

Keywords: Meta-analysis; Systematic review; Wild-type transthyretin amyloidosis cardiomyopathy 


\section{Key Summary Points}

This is the first meta-analysis of male proportion in patients with ATTRwt.

Studies conducted to date suggest that ATTRwt disproportionately affects male patients.

In the primary analysis, the male proportion was $86.9 \%$ (95\% CI: 81.5-91.6\%).

The mean age at diagnosis is a determinant of the gender distribution.

\section{DIGITAL FEATURES}

This article is published with digital features to facilitate understanding of the article. You can access the digital features on the article's associated Figshare page. To view digital features for this article go to https://doi.org/10.6084/m9. figshare.13214594.

\section{INTRODUCTION}

Transthyretin amyloidosis cardiomyopathy (ATTR-CM) is a rare, progressively debilitating, fatal disease [1]. ATTR-CM is caused by instability of the transthyretin tetramer, leading to the formation of amyloid deposited in the heart, which, subsequently, impairs its function [1]. Two different subtypes of ATTR-CM are clinically identified, hereditary ATTR-CM (hATTR) and wild-type ATTR-CM (ATTRwt). HATTR is caused by a mutation in the transthyretin (TTR) gene and is transmitted from parents to offspring in an autosomal dominant pattern [2]. As a result, hereditary ATTR-CM generally affects men and women equally, although, depending on the mutation, men usually have an earlier onset and more aggressive course of disease [3]. On the other hand, in ATTRwt, the TTR protein forming the amyloid is not mutated; instead, the disease is caused by age-related changes in the wild-type TTR $[4,5]$. Therefore, it is typically seen in patients older than 65 years of age, while hATTR can affect patients as young as 30 years of age [2, 6-11].

ATTRwt's epidemiology is poorly characterized; an estimation of ATTRwt prevalence ranges from 2.8 to 3.9 cases per 10,000 in the European Union [12]. Patients with ATTRwt experience progression in heart failure (HF) symptoms (e.g., dyspnea, fatigue, and edema), leading to increasing impairment and death, primarily caused by HF [10, 13-15]. Untreated, ATTRwt is associated with a median survival of approximately 3.5 years, post-diagnosis $[16,17]$. Delays in diagnosis are common in the current treatment landscape, which further shortens the survival time in some patients [18-21]. Thus, there is a need to characterize these patients better and subsequently provide optimal care.

Based on the available evidence from large cohort studies, it is generally believed that ATTRwt is more common in male patients $[22,23]$. This may hinder the identification of female patients in need of optimal care. Nevertheless, the gender distribution of patients diagnosed with ATTRwt cardiomyopathy was never formally established in the literature. Hence, this study aimed to conduct the first meta-analysis of gender distribution in ATTRwt patients and identify potential effect modifiers.

\section{METHODS}

\section{Systematic Literature Review}

A systematic literature review was conducted and reported according to the Preferred Reporting Items for Systematic Reviews and Meta-Analyses Statement [24]. The search was performed on February 19, 2020 with no restriction on publication date. The bibliographic databases of PubMed, Embase, and Cochrane Collaboration Central Register of Clinical Trials were used to identify published studies on ATTRwt populations specifically. The only criterion for the inclusion of the studies for analysis was reporting the male or female proportion of patients with ATTRwt. Reports 
published in the English language were considered irrespective of study design, intervention, or study outcomes. Studies reporting the male proportion in a conference abstract or a subgroup population were also considered. Supplementary material Table 1 presents the search syntax and the hits per database.

A rigorous approach was followed in the study selection stage. Two independent reviewers performed the screening, and disputes relating to eligibility were resolved through discussion between reviewers until consensus, or through consultation with a third reviewer. First, all duplicate studies were excluded. Second, for each identified publication, the title and the abstract were assessed against the eligibility criteria. Finally, for those relevant records, or for which the relevance was still unclear based on the title or abstract, full-text reports were obtained and screened for relevance. If any systematic reviews and metaanalyses were identified, they were excluded at the title/abstract screening stage. However, the full texts of the reports were acquired and handsearched to find any additional relevant primary studies not identified through the database searches. Data extraction was carried out in a prespecified Excel grid. Data extraction items included information on study characteristics (authors, recruitment years, country and city, clinical center, sample size, study design and method of diagnosis), patient population characteristics (gender distribution, mean age at diagnosis, and presence of comorbidities like atrial fibrillation or carpal tunnel syndrome). Additionally, reported differences in baseline characteristics by gender were extracted.

Since ATTRwt is a rare disease, many specialized amyloidosis centers tend to use the patient data collected by them to answer different research questions. Subsequently, patients included in these different studies are overlapping. A set of unique studies was identified systematically to avoid double-counting of the same patient population. First, all the identified studies from the qualitative analysis were grouped based on the study center. Second, the unique studies were selected based on the following factors: authors, recruitment years, and sample size. If more than one study reported data from the same database, the study with the largest sample size was included, and the other studies were excluded from the quantitative analysis. Finally, the list with the studies that did not include overlapping population was used in the quantitative analysis to estimate the gender proportion for ATTRwt patients. The methodological quality of these unique studies was accessed using the Downs and Black checklist [25]. The methodological quality assessment did not impact subsequent decisions to include or exclude studies in the quantitative analyses. The bias across studies was assessed using a Funnel plot [26-28].

\section{Meta-Analysis}

Meta-analysis is a statistical examination that combines the results from individual studies to derive meaningful conclusions about an outcome of interest [29]. The estimations and findings from meta-analyses may be more accurate compared to those derived from individual studies [29]. In this study, pooled male proportion estimates were calculated using the DerSimonian-Laird random-effects model with Freeman-Tukey double arcsine transformation $[30,31]$. When meta-analyzing proportions, it is usually advantageous to first transform the proportions into a measure that has better statistical properties (i.e., a sampling distribution that is closer to a normal distribution and whose sampling variance can be better approximated). A transformation that works particularly well for normalizing and variancestabilizing the sampling distribution of proportions is the Freeman-Tukey (double arcsine) transformation [32]. The corresponding backtransformation equation was derived by Miller [33]. This approach does not require making any adjustments to the observed data, even when proportions are equal to 1 or 0 .

The statistical heterogeneity among the studies was assessed by the Cochran's $Q$ test and the $I^{2}$ statistic [34]. Given the diverse nature of studies and the likely heterogeneity, we applied random-effects models to carry out meta-analysis by the Der-Simonian Laird method [30]. Generally, a $p$ value $\leq 0.10$ for the Cochran's 
$Q$ test or an $I^{2} \geq 50 \%$ was suggestive of significance among-study heterogeneity [34].

\section{Primary Analysis}

For the primary analysis, the pooled male proportion estimate was calculated based on all identified unique studies. Effect modifier is a variable that differentially (positively and negatively) modifies the observed meta-analysis outcome: male proportion in this study. Effect modifiers can distort estimate measures and mislead interpretations [35]. The exploration of effect modification in meta-analysis is essential since the presence of unaccounted covariate interactions can cause confounding and bias. There is no objective test to decide whether a variable is an effect modifier or not. However, subset analysis or meta-regression can provide more insights into the impact of identified effect modifiers. Therefore, in secondary analyses, we attempted to identify potential effect modifiers of gender distribution.

\section{Secondary Analyses}

First, analyses were repeated in subsets of studies based on different available covariates, including sample size, recruitment years, geography, study design, mean age at diagnosis, and method of diagnosis. Median cut-off values were used to create subsets based on the sample size and mean age at diagnosis. Due to changes in diagnostic criteria and greater awareness of treatment availability, analysis in subsets based on recruitment years (before 2010 vs. after 2010) was performed. A subset analysis based on specific detailed demographic characteristics, including race, was not feasible due to underreporting. Still, a subset analysis based on the study location, Asian studies versus non-Asian studies, was feasible due to the availability of several Asian studies. In the study design subset, the male proportion in prospective studies was compared to the same in retrospective studies. Typically, retrospective studies might be of lower quality compared to prospective studies [36]. Finally, studies with at least one patient identified through an autopsy were compared to other studies assuming that autopsies may be more objective and less subjective to physician bias.

Second, additional meta-regression analyses were performed. Thus, the effect of different variables in the male proportion estimate could be interpreted when controlling for likely effect modifiers.

Third, whenever reported, differences in baseline characteristics by gender in any of the retrieved studies were extracted and summarized.

The meta-analysis and the meta-regression analysis were conducted using the "metafor" $\mathrm{R}$ package and the JASP software, respectively [37-39].

This article is based on previously conducted studies and does not contain any new studies with human participants or animals performed by any of the authors.

\section{RESULTS}

\section{Included Studies}

Supplementary material Fig. 1 shows the flow of the study selection process. After duplicate removal, of the 3201 potentially relevant hits, 198 hits qualified for full-text screening. Subsequently, 104 reports fulfilled the eligibility criteria. The list of the total records included in this review is presented in Supplementary material Table 2.

Twenty-eight reports qualified as unique studies for further quantitative analysis $[19,20,22,40-64]$. Table 1 presents an overview of the characteristics of these studies. In total, 2542 patients were included in these studies. Significantly more studies were conducted in non-Asian countries $(n=23)$ compared to Asian countries $(n=5)$. The mean age at diagnosis ranged from 74.0 to 93.8 years. Few studies used autopsies $(n=5)$ to identify eligible patients $[20,46,61,62,64]$. Seventeen studies used endomyocardial biopsy to diagnose at least one patient $[19,20,22,42,43,46,47$, $50-53,55,56,60-62,64]$, nine studies used either extracardiac biopsy or other diagnostic methods (e.g., scintigraphy) [41, 44, 45, 48, 54, 


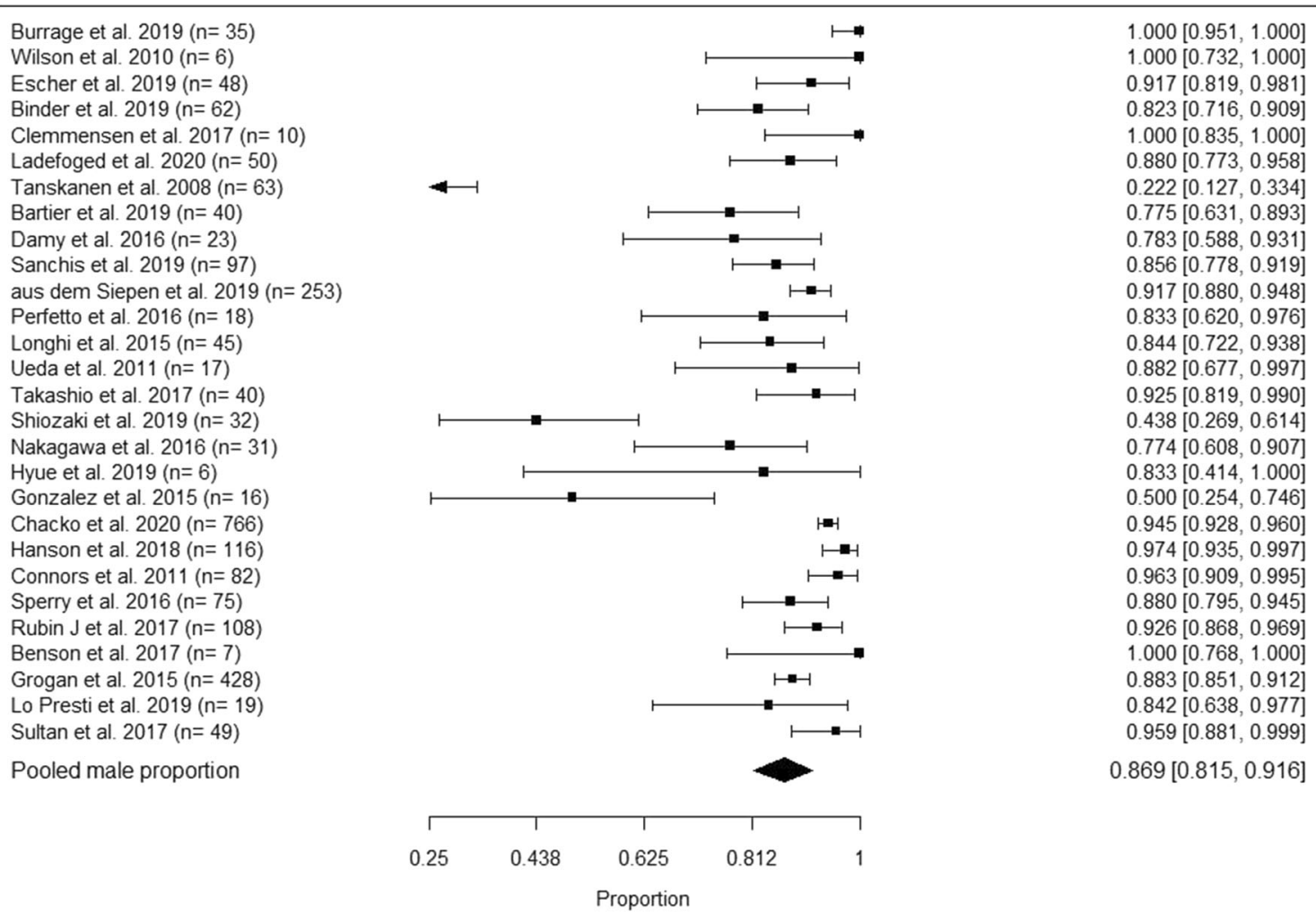

Fig. 1 Male proportion estimate in the primary analysis-Forest plot

57-59, 63] and two studies did not report any diagnostic methods [40, 49]. Further detailed information on the characteristic of these studies and the quality of individual studies are presented in Supplementary material Table 3 and Supplementary material Table 4, respectively. The checklist used for the quality assessment of the individual studies is presented in Supplementary material Table 5.

A visual examination of the funnel plot (see Supplementary material Fig. 2) shows that the risk of publication bias is unlikely. Three studies reported the proportion of male patients of 50\% or less: Tanskanen et al., Shiozaki et al., and Gonzalez et al. [20, 62, 63]. On the other hand, four studies included only male patients: Clemmensen et al., Burrage et al., Benson et al. and Wilson et al. [40, 49, 55, 56].

\section{Primary Analysis Results}

Figure 1 displays the male proportion (per unique study and pooled) along with a 95\% confidence interval (CI). The pooled estimate of male proportion is $86.9 \%$ (95\% CI $81.5-91.6 \%)$.

\section{Secondary Analyses Results}

\section{Subset Analyses}

Table 2 summarizes pooled male proportion estimates in the predefined subset of studies. Only the subset analysis based on mean age at diagnosis showed meaningful differences: 95\% CIs are not overlapping in defined subsets. Studies, including older ATTRwt patients ( $\geq 80$ years) at baseline $[19,20,41,48,53$, $54,58,62,63]$, reported lower male proportion compared with studies including younger ATTRwt patients ( $<80$ years) at baseline $[22,40$, 42-44, 46, 47, 49, 50, 56, 57, 59, 61, 64]: 69.5\% $(95 \% \quad$ CI $\quad 49.3-86.7 \%) \quad$ vs. $92.7 \% \quad(95 \% \quad$ CI $89.8-95.2 \%)$, respectively. The results of the individual studies and the pooled estimates are also shown in Fig. 2. Non-significant differences were observed in studies that had recruited patients before 2010 vs. those which had 
Table 1 Overview of the characteristics of included studies in the quantitative analysis

\begin{tabular}{|c|c|c|}
\hline Variable & $\begin{array}{l}\text { Number of } \\
\text { studies }\end{array}$ & $\begin{array}{l}\text { Percentage of } \\
\text { studies (\%) }\end{array}$ \\
\hline All studies & 28 & 100 \\
\hline \multicolumn{3}{|l|}{ Country } \\
\hline Australia & 2 & 7.1 \\
\hline Austria & 2 & 7.1 \\
\hline Denmark & 2 & 7.1 \\
\hline Finland & 1 & 3.6 \\
\hline France & 3 & 10.7 \\
\hline Germany & 1 & 3.6 \\
\hline Italy & 2 & 7.1 \\
\hline Japan & 4 & 14.3 \\
\hline South Korea & 1 & 3.6 \\
\hline Spain & 1 & 3.6 \\
\hline UK & 1 & 3.6 \\
\hline USA & 8 & 28.6 \\
\hline \multicolumn{3}{|l|}{ Sample size } \\
\hline $\begin{array}{l}50 \text { patients and } \\
\text { over }\end{array}$ & 11 & 39.3 \\
\hline $\begin{array}{l}\text { Less than } 50 \\
\text { patients }\end{array}$ & 17 & 60.7 \\
\hline \multicolumn{3}{|l|}{ Data collection $^{a}$} \\
\hline Before 2010 & 4 & 14.3 \\
\hline After 2010 & 7 & 25.0 \\
\hline \multicolumn{3}{|l|}{ Region } \\
\hline Asia & 5 & 17.9 \\
\hline No-Asia & 23 & 82.1 \\
\hline \multicolumn{3}{|l|}{ Study type } \\
\hline Prospective & 9 & 32.1 \\
\hline Retrospective & 19 & 67.9 \\
\hline \multicolumn{3}{|c|}{ Method of diagnosis include autopsy } \\
\hline Yes & 5 & 17.9 \\
\hline No & 23 & 82.1 \\
\hline \multicolumn{3}{|c|}{ Mean age at diagnosis ${ }^{\mathrm{b}}$} \\
\hline
\end{tabular}

Table 1 continued

\begin{tabular}{lcl}
\hline Variable & $\begin{array}{l}\text { Number of } \\
\text { studies }\end{array}$ & $\begin{array}{l}\text { Percentage of } \\
\text { studies (\%) }\end{array}$ \\
\hline 80 and over & 9 & 32.1 \\
Less than 80 & 14 & 50.0 \\
\hline
\end{tabular}

a The time of data collection for $17 / 28$ studies (60.7\%) extended across the 'before 2010' and 'after 2010' periods; these studies were not included

${ }^{b}$ Mean age at diagnosis was not reported in 5/28 studies (17.9\%); these studies were not included

recruited patients after 2010, Asian studies vs. non-Asian studies, and autopsy studies vs. other studies (see Table 2 for more details). In contrast, male proportions were similar to the primary analysis for studies with $>50$ patients vs. studies with $\leq 50$ patients and in prospective vs. retrospective studies.

\section{Meta-Regressions}

For the meta-regression, we considered three analyses controlling for mean age at diagnosis only or geography (Asian studies vs. non-Asian studies), method of diagnosis (autopsy studies vs. other studies), or both.

Table 3 presents results from performed meta-regressions. When controlled the metaanalysis for age, studies including older ATTRwt patients ( $\geq 80$ years at diagnosis) had a $29.1 \%$ ( $p$ value $<0.001)$ lower male proportion compared to studies including younger ATTRwt patients ( $<80$ years at diagnosis). This difference remained significant even after adjusting for geography or method of diagnosis. Also, studies using autopsy as a method of diagnosis had a $21.1 \%$ ( $p$ value 0.002 ) or $20.6 \%$ ( $p$ value 0.003 ) lower male proportion compared to other studies after adjusting for age only or both age and geography, respectively. On the other hand, after adjusting for age at diagnosis or method of diagnosis, the male proportion did not differ in Asian vs. non-Asian studies. 
Table 2 Pooled male proportion estimates in the predefined subset of studies

\begin{tabular}{|c|c|c|c|c|}
\hline Subgroup & Sample size per subgroup & Male proportion (\%) & Lower CI (\%) & Upper CI (\%) \\
\hline \multicolumn{5}{|l|}{ Study sample size } \\
\hline$>50$ patients & 2100 & 86.9 & 79.3 & 93.1 \\
\hline$\leq 50$ patients & 442 & 86.7 & 78.4 & 93.5 \\
\hline \multicolumn{5}{|l|}{ Data selection $^{\mathrm{a}}$} \\
\hline Before 2010 & 200 & 84.1 & 36.3 & 100 \\
\hline After 2010 & 200 & 91.9 & 83.1 & 98.1 \\
\hline \multicolumn{5}{|l|}{ Region } \\
\hline Asian studies & 126 & 78.3 & 56.5 & 94.5 \\
\hline Non-Asia studies & 2416 & 88.3 & 82.9 & 93.0 \\
\hline \multicolumn{5}{|l|}{ Method of diagnosis } \\
\hline Autopsy studies & 588 & 69.3 & 36.9 & 93.9 \\
\hline Other studies & 1954 & 90.8 & 87.3 & 93.9 \\
\hline \multicolumn{5}{|l|}{ Study design } \\
\hline Prospective & 1081 & 88.8 & 80.9 & 95.0 \\
\hline Retrospective & 1461 & 86.1 & 78.4 & 92.5 \\
\hline \multicolumn{5}{|c|}{ Mean age at diagnosis ${ }^{\mathrm{b}}$} \\
\hline$\geq 80$ years & 341 & 69.5 & 49.3 & 86.7 \\
\hline$<80$ years & 1911 & 92.7 & 89.8 & 95.2 \\
\hline
\end{tabular}

a The time of data collection for 17/28 studies (60.7\%) extended across the 'before 2010' and 'after 2010' periods; these studies were not included

b Mean age at diagnosis was not reported in 5/28 studies (17.9\%); these studies were not included

\section{Reported Differences in Baseline Characteristics by Gender in Individual \\ Studies}

Out of the total of 104 studies, seven reports detailed differences in the baseline characteristics by gender in ATTRwt patients [11, 19, 20, 43, 46, 62, 65]. See Supplementary Material Table 6.

Differences in the age of male patients vs. female patients were reported in all seven studies [11, 19, 20, 46, 62, 65, 66]. In Ladefoged et al. 2020, the average age of females at baseline was significantly higher than that of males: $86.4 \pm 2.6$ years vs. $81.1 \pm 0.9$ years, respectively [19]. Likewise, in Gonzalez-Lopez et al., female patients were significantly older than male patients at the time of symptom onset and diagnosis, 82.3 vs. 76.1 , and 83.9 vs. 77.4, respectively [11]. Two studies, Ueda et al. and Shiozaki et al., reported differences between female and male patients at the age of death, $92.5( \pm 13.4)$ vs. $78.5( \pm 9.7)$ and $88.4( \pm 6)$ vs. $85.8( \pm 10.5)[46,62]$.

Other differences reported between males and females were related to disease severity. Tanskanen et al. reported that the severity of ATTRwt was significantly associated with male gender [20]. Three studies, aus dem Siepen et al., Gonzalez-Lopez et al., and Yamamoto et al. reported that females presented lower values for interventricular septal [11, 66, 67] thickness, posterior wall thickness, and left ventricular 


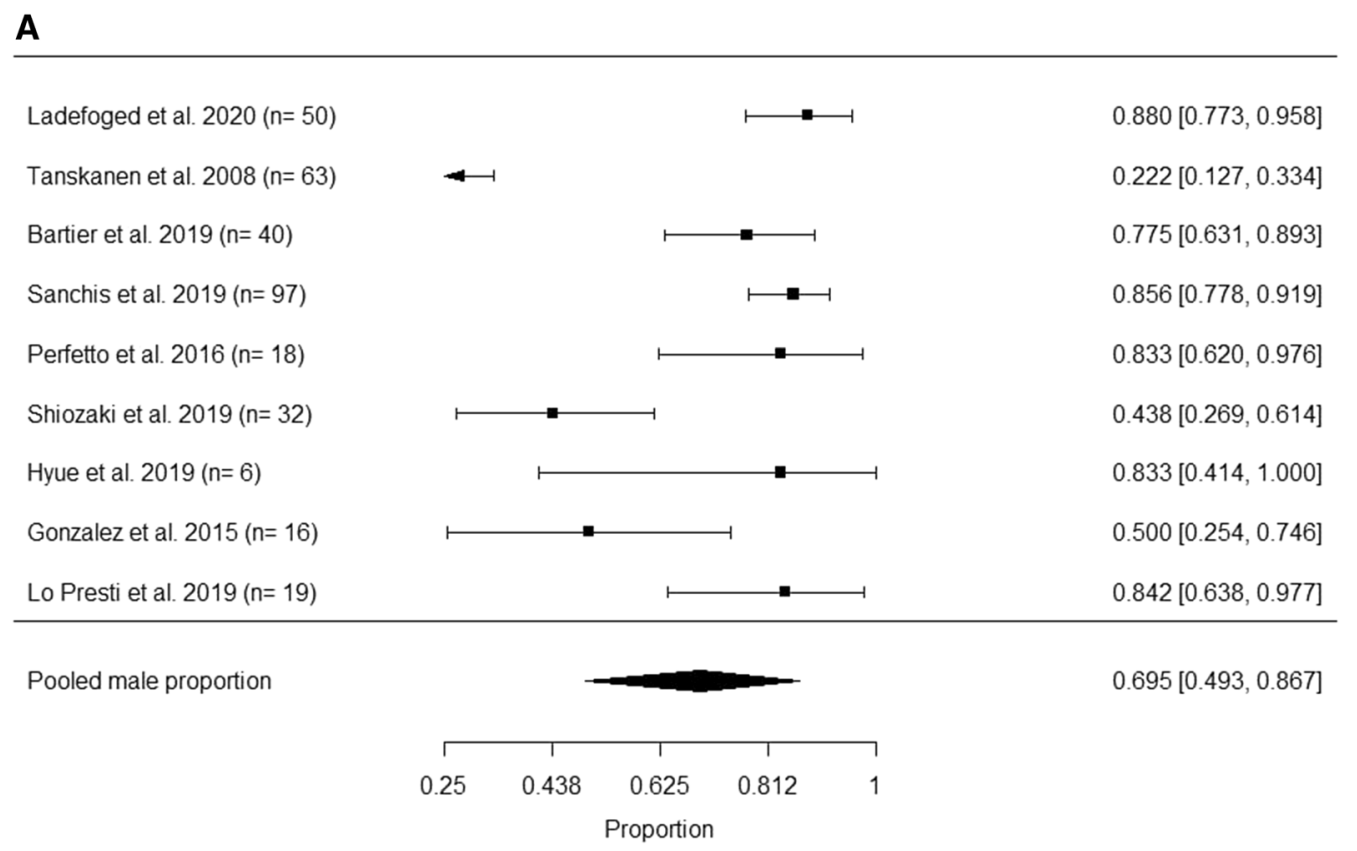

B

\begin{tabular}{ll}
\hline Burrage et al. $2019(\mathrm{n}=35)$ & $1.000[0.951,1.000]$ \\
Wilson et al. $2010(\mathrm{n}=6)$ & $1.000[0.732,1.000]$ \\
Escher et al. $2019(\mathrm{n}=48)$ & $0.917[0.819,0.981]$ \\
Clemmensen et al. $2017(\mathrm{n}=10)$ & $1.000[0.835,1.000]$ \\
aus dem Siepen et al. $2019(\mathrm{n}=253)$ & $0.917[0.880,0.948]$ \\
Longhi et al. $2015(\mathrm{n}=45)$ & $0.844[0.722,0.938]$ \\
Ueda et al. $2011(\mathrm{n}=17)$ & $0.882[0.677,0.997]$ \\
Takashio et al. $2017(\mathrm{n}=40)$ & $0.925[0.819,0.990]$ \\
Nakagawa et al. $2016(\mathrm{n}=31)$ & $0.774[0.608,0.907]$ \\
Chacko et al. $2020(\mathrm{n}=766)$ & $0.945[0.928,0.960]$ \\
Sperry et al. $2016(\mathrm{n}=75)$ & $0.880[0.795,0.945]$ \\
Rubin J et al. $2017(\mathrm{n}=108)$ & $0.926[0.868,0.969]$ \\
Grogan et al. $2015(\mathrm{n}=428)$ & \\
Sultan et al. $2017(\mathrm{n}=49)$ &
\end{tabular}

Fig. 2 a Male proportion estimate in different studies stratified by baseline mean age at diagnosis: $\mathbf{a} \geq 80$ years. b Male proportion estimate in different studies stratified by baseline mean age at diagnosis: $\mathbf{b}<80$ years

diastolic diameter compared to males. Additional variations, in particular, include significant differences between females and males in the New York Heart Association (NYHA) classification and glomerular filtration rate scores 3.0
( \pm 0.4$)$ vs. $2.5( \pm 0.7)$ and $86.0( \pm 33.2)$ vs. 66.7 $( \pm 21.4)$, respectively [66]. Finally, GonzalezLopez et al., reported that females were diagnosed non-invasively more frequently compared to males and presented with better left 
Table 3 Results from the different meta-regression analyses

\begin{tabular}{lccr}
\hline $\begin{array}{l}\text { Meta- } \\
\text { regression }\end{array} \quad \begin{array}{l}\text { Male proportion } \\
(\%)\end{array}$ & $\begin{array}{l}\text { Standard } \\
\text { error }\end{array}$ & $p$ value \\
\hline Controlling for age at diagnosis & & \\
Intercept & 91.0 & 0.040 & $<0.001$ \\
Age & -29.1 & 0.073 & $<0.001$ \\
Controlling for age at diagnosis, method of diagnosis, and \\
geography & & & \\
Intercept & 91.4 & 0.095 & $<0.001$ \\
Asian & 3.8 & 0.094 & 0.683 \\
Autopsy & -20.6 & 0.070 & 0.003 \\
Age & -26.6 & 0.066 & $<0.001$ \\
Controlling for age at diagnosis and method of diagnosis \\
Intercept & 95.1 & 0.036 & $<0.001$ \\
Autopsy & -21.1 & 0.065 & 0.002 \\
Age & -27.0 & 0.068 & $<0.001$ \\
Controlling for age at diagnosis and geography & \\
Intercept & 83.1 & 0.097 & $<0.001$ \\
Asian & 9.0 & 0.102 & 0.001 \\
Age & 28.5 & & \\
\hline
\end{tabular}

ventricular ejection fraction $75 \%$ vs. $29 \%$ and 59 vs. 51, respectively [11].

\section{DISCUSSION}

This study is the first meta-analysis to estimate the gender distribution in patients with ATTRwt. We discovered three key findings. First, among all unique studies, the male proportion in patients with ATTRwt was $86.9 \%$ (95\% CI 81.5-91.6\%), indicating a male to female ratio of approximately $7: 1$. Second, ATTRwt patients of older age were significantly more likely to be female. Third, patients diagnosed by autopsy were significantly more likely to be female, a result that remained consistent even after adjusting for age.
While still understudied in ATTRwt patients, the observed gender imbalance could involve a combination of sex-specific biological factors and diagnostic challenges in female patients. In cardiovascular disease, certain female sex hormones, particularly estrogen, could be cardioprotective [68]. However, similar guidelines for the identification of ATTR-CM for both sexes (LV wall thickness $>12 \mathrm{~mm}$ ) but larger cardiac anatomy in males compared to females may result in disease underdiagnosis of the latter as they are less likely to meet this threshold [69]. Other studies suggest ATTRwt may manifest differently in female patients resulting in more atypical symptoms compared to men [70, 71] which may pose additional diagnostic challenges. Individual studies in our review reported that the severity of ATTRwt was overall lower in females vs. males with favorable measures related to NYHA class, left ventricular ejection fraction interventricular septal thickness, posterior wall thickness, and left ventricular diastolic diameter $[11,20,66]$. In line with our findings, earlier onset and more severe disease are more common in male patients with hATTR $[4,5]$. Therefore, both the older age of presentation and milder symptoms in female patients would contribute jointly to lower diagnosis rates. Literature suggests that gender imbalances are common in ATTR-CM [69]. Increasing the awareness of these factors among clinicians, in particular, implementing non-invasive techniques such as nuclear scintigraphy, could potentially increase the diagnosis among women if currently underdiagnosed [72]. Besides, the diagnosis of associated features, including carpal tunnel syndrome and lumbar spinal stenosis, raise suspicion, and may afford a means for early diagnosis [44, 73]. Nevertheless, more clinical data on how ATTRwt morbidity and mortality are different in female compared to male patients are needed. In a previous study that examined gender-based differences in over 200 ATTRwt patients, Kristen et al., found a longer delay in the initiation of symptoms and diagnosis of ATTRwt in females compared to male patients [74]. A milder or more atypical disease progression in females could result in diagnosis at an older age, a trend observed in a variety of studies [11, 19, 20, 43, 46, 62, 65]. 
This observation was also confirmed in our second finding, as there were $69.5 \%$ males $(95 \%$ CI $49.3-86.7 \%)$ vs. $92.7 \%$ males (95\% CI $89.8-95.2 \%)$ in patients over 80 years vs. patients under 80 years of age, respectively. After controlling for geography or method of diagnosis in the meta-regressions, studies including older ATTRwt patients had significantly lower male proportion compared to studies, including younger ATTRwt patients. The older age at diagnosis in females might be influenced by survival bias, i.e., on average, a female person lives longer than a male person. Male proportion did not significantly differ in Asian vs. non-Asian studies after adjusted for age in the meta-regression, implying that the older age partly explains the difference between Asian and non-Asian studies at diagnosis in Asian studies.

Our third finding showed that males were significantly less likely to be diagnosed in autopsies compared to females (coeff. - 21.1, $p=0.002$ ) after controlling for age and may support the narrative that ATTRwt is underdiagnosed in women. Other studies have also found that females are more likely to be diagnosed post-mortem vs. premortem [23]. Other gender-specific trends in diagnostic methods cite that females were more likely to be diagnosed non-invasively than invasively [11].

There are sizeable strengths of this review. First, the results reflect a systematic review of all data available for ATTRwt patients, including both Western and Asian populations. Second, the synthesis of the male proportion applied suitable methods for meta-analysis of proportions. Third, we attempted to adjust for confounders employing subset analysis and metaregression. Our results lay the necessary groundwork for future research on gender differences in diagnosis and disease burden of ATTRwt.

On the other hand, there are a few limitations to this review. First, regarding the subset analysis based on the recruitment years, we acknowledge that due to recent changes in the diagnostic methods (i.e., use of scintigraphy to diagnose ATTR without biopsy), it would have been better to dichotomize the data on studies recruiting patients before and after 2016.
However, this analysis was not feasible due to the limited number of studies with patients recruited after 2016. Second, studies with a smaller sample size (frequently conducted at academic medical centers within affluent cities) often have a lower degree of randomness and representation of the general population. Third, while every effort was made to identify unique populations by years of data collection and name of the study center, there remains the possibility of overlapping study populations. Fourth, selection or referral bias within the included studies can be a confounder for the overall analysis, which makes it unclear whether the observed male predominance is due to under-diagnosis of women with ATTRwt or a true male predominance of disease. However, subset analyses based on a higher sample size, i.e., large cohort studies and using autopsy as a method of diagnosis, might be more reflective of the general ATTRwt population. Additional population-based studies are needed to further confirm our findings. Moreover, had we included languages other than English in our search strategy, it is possible that we would have encountered other relevant studies that were not included in this review. Most of our studies were in Western Europe or North America, with no representation from Latin American, Caribbean, Middle Eastern, or African countries. Finally, with only seven studies that stratify by gender, we have limited insight into the differences in clinical and baseline characteristics by gender for ATTRwt patients.

\section{CONCLUSIONS}

This is the first meta-analysis to estimate the gender distribution of ATTRwt patients based on existing literature. While we confirm that males are predominantly affected, this analysis also shows that the proportion of males was significantly impacted by the age at diagnosis and method diagnosis. This may suggest important gender-based differences in the clinical manifestation and diagnostic challenges of ATTRwt in females that warrant future research. 


\section{ACKNOWLEDGEMENTS}

Funding. The study and the Journal's Rapid Service Fee were funded by Pfizer.

Authorship. All named authors meet the International Committee of Medical Journal Editors (ICMJE) criteria for authorship for this article, take responsibility for the integrity of the work as a whole, and have given their approval for this version to be published.

Authorship Contributions. Conception and design: MR, NF, and MH. Collection and assembly of data: FK, AG, and MH. Data analysis and interpretation: MR, NF, FK, and $\mathrm{MH}$. Manuscript writing: All authors. Final approval of manuscript: All authors. Accountable for all aspects of the work: All authors.

Disclosures. Mark Rozenbaum and Nils Fischer are employees of Pfizer. Florint Kroi, Ana Gezin, and Mahmoud Hashim are employees of Ingress-Health. Florint Kroi, Ana Gezin, and Mahmoud Hashim are employees of IngressHealth who were paid consultants to Pfizer in connection with performing the review and analyses and developing the manuscript.

Compliance with Ethics Guidelines. This article is based on previously conducted studies and does not contain any new studies with human participants or animals performed by any of the authors.

Data Availability. All data generated or analyzed during this study are included in this published article/as supplementary information files.

Open Access. This article is licensed under a Creative Commons Attribution-NonCommercial 4.0 International License, which permits any non-commercial use, sharing, adaptation, distribution and reproduction in any medium or format, as long as you give appropriate credit to the original author(s) and the source, provide a link to the Creative Commons licence, and indicate if changes were made. The images or other third party material in this article are included in the article's Creative Commons licence, unless indicated otherwise in a credit line to the material. If material is not included in the article's Creative Commons licence and your intended use is not permitted by statutory regulation or exceeds the permitted use, you will need to obtain permission directly from the copyright holder. To view a copy of this licence, visit http:// creativecommons.org/licenses/by-nc/4.0/.

\section{REFERENCES}

1. Rapezzi C, Quarta CC, Riva L, et al. Transthyretinrelated amyloidoses and the heart: a clinical overview. Nat Rev Cardiol. 2010;7(7):398-408. https:// doi.org/10.1038/nrcardio.2010.67 20479782]).

([PMID:

2. Mankad AK, Shah KB. Transthyretin cardiac amyloidosis. Curr Cardiol Rep. 2017;19(10):97. https:// doi.org/10.1007/s11886-017-0911-5 28840452]).

3. Ruberg FL, Berk JL. Transthyretin (TTR) cardiac amyloidosis. Circulation. 2012;126(10):1286-300. https://doi.org/10.1161/circulationaha.111.078915 ([PMID: 22949539]).

4. Arvidsson S, Pilebro B, Westermark P, Lindqvist P, Suhr OB. Amyloid cardiomyopathy in hereditary transthyretin V30M amyloidosis-impact of sex and amyloid fibril composition. PLoS ONE. 2015. https://doi.org/10.1371/journal.pone.0143456 ([PMID: 26600306]).

5. Santos D, Coelho T, Alves-Ferreira M, et al. The hidden story behind gender differences in familial amyloid polyneuropathy (FAP) ATTRV30M. Orphanet J Rare Dis. 2015;10(Suppl 1):O4. https:// doi.org/10.1186/1750-1172-10-S1-O4.

6. Gertz MA. Hereditary ATTR amyloidosis: burden of illness and diagnostic challenges. Am J Manag Care. 2017;23(7 Suppl):S107-12 ([PMID: 28978215]).

7. Rapezzi C, Quarta CC, Obici L, et al. Disease profile and differential diagnosis of hereditary transthyretin-related amyloidosis with exclusively cardiac phenotype: an Italian perspective. Eur Heart J. 2013;34(7):520-8. https://doi.org/10.1093/ eurheartj/ehs123 ([PMID: 22745357]).

8. Arbustini E, Merlini G. Early identification of transthyretin-related hereditary cardiac 
amyloidosis. JACC Cardiovasc Imaging. 2014;7(5): 511-4. https://doi.org/10.1016/j.jcmg.2014.03.007 ([PMID: 24831211]).

9. Rapezzi C, Lorenzini M, Longhi S, et al. Cardiac amyloidosis: the great pretender. Heart Fail Rev. 2015;20(2):117-24. https://doi.org/10.1007/ s10741-015-9480-0 ([PMID: 25758359]).

10. Donnelly JP, Hanna M. Cardiac amyloidosis: an update on diagnosis and treatment. Cleve Clin J Med. 2017;84(12 Suppl 3):12-26. https://doi.org/ 10.3949/ccjm.84.s3.02] ([PMID: 29257735]).

11. González-López E, López-Sainz Á, Garcia-Pavia P. Diagnosis and treatment of transthyretin cardiac amyloidosis. Progress and hope. Rev Esp Cardiol (Engl Ed). 2017;70(11):991-1004. https://doi.org/ 10.1016/j.rec.2017.05.036 ([PMID: 28870641]).

12. European Medicines Agency-Committee for Orphan Medicinal Products. Orphan maintanence assessment report for Vyndaqel: European medicines agency; 2020. Available from: URL: https:// www.ema.europa.eu/en/documents/orphanmaintenance-report-post/vyndaqel-orphanmaintenance-assessment-report-postauthorisation_en.pdf.

13. Castaño A, Drachman BM, Judge D, Maurer MS. Natural history and therapy of TTR-cardiac amyloidosis: emerging disease-modifying therapies from organ transplantation to stabilizer and silencer drugs. Heart Fail Rev. 2015;20(2):163-78. https://doi.org/10.1007/s10741-014-9462-7

([PMID: 25408161]).

14. Grogan M, Dispenzieri A, Gertz MA. Light-chain cardiac amyloidosis: strategies to promote early diagnosis and cardiac response. Heart. 2017;103(14):1065-72. https://doi.org/10.1136/ heartjnl-2016-310704 ([PMID: 28456755]).

15. Nativi-Nicolau J, Maurer MS. Amyloidosis cardiomyopathy: update in the diagnosis and treatment of the most common types. Curr Opin Cardiol. 2018;33(5):571-9. https://doi.org/10.1097/ HCO.0000000000000547 ([PMID: 30015648]).

16. Ruberg FL, Maurer MS, Judge DP, et al. Prospective evaluation of the morbidity and mortality of wildtype and V122I mutant transthyretin amyloid cardiomyopathy: the Transthyretin Amyloidosis Cardiac Study (TRACS). Am Heart J. 2012;164(2):222228.e1. https://doi.org/10.1016/j.ahj.2012.04.015 ([PMID: 22877808]).

17. Maurer MS, Elliott P, Comenzo R, Semigran M, Rapezzi C. Addressing common questions encountered in the diagnosis and management of cardiac amyloidosis. Circulation. 2017;135(14):1357-77. https://doi.org/10.1161/circulationaha.116.024438 ([PMID: 28373528]).

18. Winburn I, Ishii T, Sumikawa T, Togo K, Yasunaga $\mathrm{H}$. Estimating the prevalence of transthyretin amyloid cardiomyopathy in a large in-hospital database in Japan. Cardiol Ther. 2019;8(2):297-316. https://doi.org/10.1007/s40119-019-0142-5 ([PMID: 31376091]).

19. Ladefoged B, Dybro A, Povlsen JA, Vase H, Clemmensen TS, Poulsen SH. Diagnostic delay in wildtype transthyretin cardiac amyloidosis-a clinical challenge. Int J Cardiol. 2020;304:138-43. https:// doi.org/10.1016/j.ijcard.2019.12.063 32033783]).

20. Tanskanen M, Peuralinna T, Polvikoski T, et al. Senile systemic amyloidosis affects $25 \%$ of the very aged and associates with genetic variation in alpha2-macroglobulin and tau: a population-based autopsy study. Ann Med. 2008;40(3):232-9. https:// doi.org/10.1080/07853890701842988] 18382889]).

21. Halatchev IG, Zheng J, Ou J. Wild-type transthyretin cardiac amyloidosis (ATTRwt-CA), previously known as senile cardiac amyloidosis: clinical presentation, diagnosis, management and emerging therapies. J Thorac Dis. 2018;10(3):21034-45. https://doi.org/10.2137/jtd.2018.03.134 ([PMID: 29707360]).

22. Chacko L, Martone R, Bandera F, et al. Echocardiographic phenotype and prognosis in transthyretin cardiac amyloidosis. Eur Heart J. 2020. https:// doi.org/10.1093/eurheartj/ehz905 31950987]).

([PMID:

23. Grogan M, Scott CG, Kyle RA, et al. Natural history of wild-type transthyretin cardiac amyloidosis and risk stratification using a novel staging system. J Am Coll Cardiol. 2016;68(10):1014-20. https://doi.org/ 10.1016/j.jacc.2016.06.033 ([PMID: 27585505]).

24. Moher D, Liberati A, Tetzlaff J, Altman DG. Preferred reporting items for systematic reviews and meta-analyses: the PRISMA statement. PLoS Med. 2009;6(7):e1000097. https://doi.org/10.1371/ journal.pmed.1000097 ([PMID: 19621072]).

25. Downs SH, Black N. The feasibility of creating a checklist for the assessment of the methodological quality both of randomised and non-randomised studies of health care interventions. J Epidemiol Community Health. 1998;52(6):377-84. https:// doi.org/10.1136/jech.52.6.377 ([PMID: 9764259]).

26. Harbord RM, Egger M, Sterne JAC. A modified test for small-study effects in meta-analyses of controlled trials with binary endpoints. Stat Med. 
2006;25(20):3443-57. https://doi.org/10.1002/sim. 2380 ([PMID: 16345038]).

27. Sterne JAC, Egger M, Moher D, Boutron I. Chapter 10: Addressing reporting biases. In: biases. In: Higgins JPT, Churchill R, Chandler J, Cumpston MS. Cochrane Handbook for Systematic Reviews of Interventions version 5.2.0 2017.

28. Funnel plot tool; 2018. Available from: URL: https://improvement.nhs.uk/resources/funnelplot-tool/.

29. Haidich AB. Meta-analysis in medical research. Hippokratia. 2010;14(Suppl 1):29-37 ([PMID: 21487488]).

30. DerSimonian R, Laird N. Meta-analysis in clinical trials. Control Clin Trials. 1986;7(3):177-88. https://doi.org/10.1016/0197-2456(86)90046-2 ([PMID: 3802833]).

31. Miller JJ. The inverse of the freeman-Tukey Double arcsine transformation. Am Stat. 1978a;32(4): 138. https://doi.org/10.1080/00031305.1978. 10479283].

32. Freeman MF, Tukey JW. Transformations related to the angular and the square root. Ann Math Stat. 1950;21(4):607-11.

33. Miller GR. The current status of theory and research in interpersonal communication. Human Comm Res. 1978b;4(2):164-78. https://doi.org/10.1111/j. 1468-2958.1978.tb00606.x.

34. Higgins JPT, Thomas J, Chandler J, Cumpston M, Li T, Page MJ, Welch VA. Cochrane Handbook for Systematic Reviews of Interventions version 6.0 2019.

35. Kamangar F. Confounding variables in epidemiologic studies: basics and beyond. Arch Iran Med. 2012;15(8):508-16 ([PMID: 22827790]).

36. Vandenbroucke JP. Observational research, randomised trials, and two views of medical science. PLoS Med. 2008;5(3):e67. https://doi.org/10.1371/ journal.pmed.0050067 ([PMID: 18336067]).

37. Viechtbauer W. Conducting meta-analyses in $\mathrm{R}$ with the metafor Package. J Stat Soft. 2010. https:// doi.org/10.1837/jss.v036.i03.

38. RStudio: Integrated Development Environment for R. Boston, MA: RStudio Team; 2020. Available from: URL: http://www.rstudio.com/.

39. JASP (Version 0.12.2)[Computer software] JASP Team; 2020. Available from: URL: https://jasp-stats. org/.
40. Clemmensen TS, Eiskjær H, Mølgaard $\mathrm{H}$, et al. Abnormal coronary flow velocity reserve and decreased myocardial contractile reserve are main factors in relation to physical exercise capacity in cardiac amyloidosis. J Am Soc Echocardiogr. 2018;31(1):71-8. https://doi.org/10.1016/j.echo. 2017.09.007 ([PMID: 29111120]).

41. Sanchis K, Cariou E, Colombat M, et al. Atrial fibrillation and subtype of atrial fibrillation in cardiac amyloidosis: clinical and echocardiographic features, impact on mortality. Amyloid. 2019;26(3): 128-38. https://doi.org/10.1080/13506129.2019. 1620724 ([PMID: 31172799]).

42. Longhi S, Quarta CC, Milandri A, et al. Atrial fibrillation in amyloidotic cardiomyopathy: prevalence, incidence, risk factors and prognostic role. Amyloid. 2015;22(3):147-55. https://doi.org/10. 3109/13506129.2015.1028616 25997105]).

([PMID:

43. de Siepen F, Hein S, Prestel S, et al. Carpal tunnel syndrome and spinal canal stenosis: harbingers of transthyretin amyloid cardiomyopathy? Clin Res Cardiol. 2019;108(12):1324-30. https://doi.org/10. 1007/s00392-019-01467-1 ([PMID: 30953182]).

44. Nakagawa M, Sekijima Y, Yazaki M, et al. Carpal tunnel syndrome: a common initial symptom of systemic wild-type ATTR (ATTRwt) amyloidosis. Amyloid. 2016;23(1):58-63. https://doi.org/10. $3109 / 13506129.2015 .1135792$ 26852880]).

([PMID:

45. Connors LH, Doros G, Sam F, Badiee A, Seldin DC, Skinner M. Clinical features and survival in senile systemic amyloidosis: comparison to familial transthyretin cardiomyopathy. Amyloid. 2011;18(Suppl 1):157-9. https://doi.org/10.3109/ 13506129.2011.574354059 ([PMID: 21838471]).

46. Ueda M, Horibata $\mathrm{Y}$, Shono $\mathrm{M}$, et al. Clinicopathological features of senile systemic amyloidosis: an ante- and post-mortem study. Mod Pathol. 2011;24(12):1533-44. https://doi.org/10.1038/ modpathol.2011.117] ([PMID: 21822203]).

47. Takashio S, Yamamuro M, Izumiya Y, et al. Diagnostic utility of cardiac troponin T level in patients with cardiac amyloidosis. ESC Heart Fail. 2018;5(1): 27-35. https://doi.org/10.1002/ehf2.12203] ([PMID: 28869340]).

48. Perfetto F, Bergesio F, Grifoni E, et al. Different NTproBNP circulating levels for different types of cardiac amyloidosis. J Cardiovasc Med (Hagerstown). 2016;17(11):810-7. https://doi.org/10.2459/JCM. 0000000000000349 ([PMID: 26765991]).

49. Burrage M, Korczyk D, Mollee P. 1955 First Australian registry of patients with wild-type cardiac 
amyloidosis (ATTRwt): Queensland experience. Eur Heart J. 2017. https://doi.org/10.1093/eurheartj/ ehx502.1955.

50. Rubin J, Alvarez J, Teruya S, et al. Hip and knee arthroplasty are common among patients with transthyretin cardiac amyloidosis, occurring years before cardiac amyloid diagnosis: can we identify affected patients earlier? Amyloid. 2017;24(4): 226-30. https://doi.org/10.1080/13506129.2017. 1375908 ([PMID: 28906148]).

51. Damy T, Jaccard A, Guellich A, et al. Identification of prognostic markers in transthyretin and AL cardiac amyloidosis. Amyloid. 2016;23(3):194-202. https://doi.org/10.1080/13506129.2016.1221815 ([PMID: 27647161]).

52. Binder C, Duca F, Stelzer PD, et al. Mechanisms of heart failure in transthyretin vs. light chain amyloidosis. Eur Heart J Cardiovasc Imaging. 2019;20(5):512-24. https://doi.org/10.1093/ehjci/ jey225 ([PMID: 30649240]).

53. Bartier S, Bodez D, Kharoubi M, et al. Pharyngolaryngeal involvement in systemic amyloidosis with cardiac involvement: a prospective observational study. Amyloid. 2019;26(4):216-24. https:// doi.org/10.1080/13506129.2019.1646639 ([PMID: 31364411]).

54. Kim HM, Sohn D-W, Paeng JC. Prevalence of positive 99 mTc-DPD scintigraphy as an Indicator of the prevalence of wild-type transthyretin amyloidosis in the elderly. Int Heart J. 2019;60(3):643-7. https://doi.org/10.1536/ihj.18-345 31019172]).

([PMID:

55. Benson MD, Dasgupta NR, Rissing SM, Smith J, Feigenbaum H. Safety and efficacy of a TTR specific antisense oligonucleotide in patients with transthyretin amyloid cardiomyopathy. Amyloid. 2017;24(4):219-25. https://doi.org/10.1080/ 13506129.2017.1374946 ([PMID: 28906150]).

56. Wilson WM, Gonzales M, Voukelatos J, Morton JB. Senile cardiac amyloidosis. Intern Med J. 2010;40(6):468-9. https://doi.org/10.1111/j.14455994.2010.02250.x ([PMID: 20636833]).

57. Sperry BW, Vranian MN, Hachamovitch R, et al. Subtype-specific interactions and prognosis in cardiac amyloidosis. J Am Heart Assoc. 2016;5(3): e002877. https://doi.org/10.1161/JAHA.115. 002877 ([PMID: 27013539]).

58. Lo Presti S, Horvath SA, Mihos CG, Rajadhyaksha C, McCloskey V, Santana O. Transthyretin cardiac amyloidosis as diagnosed by $99 \mathrm{mTc}$-PYP scanning in patients with acute heart failure and preserved ejection fraction. Crit Pathw Cardiol. 2019;18(4):
$195-9$. https://doi.org/10.1097/HPC. 0000000000000183 ([PMID: 31725511]).

59. Sultan MB, Gundapaneni B, Schumacher J, Schwartz JH. Treatment with tafamidis slows disease progression in early-stage transthyretin cardiomyopathy. Clin Med Insights Cardiol. 2017;11: 1179546817730322. https://doi.org/10.1177/ 1179546817730322] ([PMID: 28951660]).

60. Hanson JLS, Arvanitis M, Koch CM, et al. Use of serum transthyretin as a prognostic indicator and predictor of outcome in cardiac amyloid disease associated with wild-type transthyretin. Circ Heart Fail. 2018;11(2):e004000. https://doi.org/10.1161/ circheartfailure.117.004000 ([PMID: 29449366]).

61. Escher F, Senoner M, Doerler J, et al. When and how do patients with cardiac amyloidosis die? Clin Res Cardiol. 2020;109(1):78-88. https://doi.org/10. 1007/s00392-019-01490-2 ([PMID: 31134330]).

62. Shiozaki T, Sato N, Hayashi T, Kobayashi K, Asamura H. Wild-type ATTR amyloidosis may be associated with unexpected death among the elderly. Leg Med (Tokyo). 2019;41:101634. https://doi.org/ 10.1016/j.legalmed.2019.101634 31731233]).

([PMID:

63. González-López E, Gallego-Delgado M, GuzzoMerello G, et al. Wild-type transthyretin amyloidosis as a cause of heart failure with preserved ejection fraction. Eur Heart J. 2015;36(38):2585-94. https://doi.org/10.1093/eurheartj/ehv338 ([PMID: 26224076]).

64. Grogan M, Scott C, Lin G, et al. Rapid Fire Abstract session: new insights in cardiomyopthies, 436 Wild type transthyretin cardiac amyloidosis: clinical characteristics, echocardiographic findings, and predictors of outcome. Eur Heart J Cardiovasc Imaging. 2015;16(suppl 2):S51-3. https://doi.org/ 10.1093/ehjci/jev254.

65. Kristen AV, Haufe S, Schonland SO, et al. Skeletal scintigraphy indicates disease severity of cardiac involvement in patients with senile systemic amyloidosis. Int J Cardiol. 2013;164(2):179-84. https:// doi.org/10.1016/j.ijcard.2011.06.123 21764155]).

66. Siepen FAD, Bauer R, Voss A, et al. Predictors of survival stratification in patients with wild-type cardiac amyloidosis. Clin Res Cardiol. 2018;107(2): 158-69. https://doi.org/10.1007/s00392-017-11671 ([PMID: 28956153]).

67. Yamamoto $\mathrm{Y}$, Onoguchi $\mathrm{M}$, Haramoto $\mathrm{M}$, et al. Novel method for quantitative evaluation of cardiac amyloidosis using (201)TlCl and (99m)Tc-PYP SPECT. Ann Nucl Med. 2012;26(8):634-43. https:// 
doi.org/10.1007/s12149-012-0627-y 22777859]).

([PMID:

68. Bhupathy P, Haines CD, Leinwand LA. Influence of sex hormones and phytoestrogens on heart disease in men and women. Womens Health (Lond Engl). 2010;6(1):77-95. https://doi.org/10.2217/whe.09. 80 ([PMID: 20088732]).

69. Bruno M, Castaño A, Burton A, Grodin JL. Transthyretin amyloid cardiomyopathy in women: frequency, characteristics, and diagnostic challenges. Heart Fail Rev. 2020. https://doi.org/10.1007/ s10741-020-10010-8 ([PMID: 32794090]).

70. Eastwood J-A, Doering LV. Gender differences in coronary artery disease. J Cardiovasc Nurs. 2005;20(5):340-51. https://doi.org/10.1097/ 00005082-200509000-00008 (quiz 352-3, PMID: 16141779).

71. Gold LD, Krumholz HM. Gender differences in treatment of heart failure and acute myocardial infarction: a question of quality or epidemiology? Cardiol Rev. 2006;14(4):180-6. https://doi.org/10. 1097/01.crd.0000194093.53005.f0

([PMID: 16788330]).

72. Gillmore JD, Maurer MS, Falk RH, et al. Nonbiopsy diagnosis of cardiac transthyretin amyloidosis. Circulation. 2016;133(24):2404-12. https://doi.org/ 10.1161/circulationaha.116.021612 27143678]).

([PMID:

73. Westermark P, Westermark GT, Suhr OB, Berg S. Transthyretin-derived amyloidosis: probably a common cause of lumbar spinal stenosis. Ups J Med Sci. 2014;119(3):223-8. https://doi.org/10.3109/ 03009734.2014.895786 (PMID: 24620715).

74. Kristen AV, Bauer R, de Siepen F, et al. Wild-type transthyretin amyloidosis in female patients. Orphanet J Rare Dis. 2015. https://doi.org/10.1186/ 1750-1172-10-S1-O9. 